\title{
Survival and low-grade glioma: the emergence of genetic information
}

\author{
Elizabeth B. Claus, MD, PhD,,2 Kyle M. Walsh, PhD, ${ }^{3}$ John K. Wiencke, PhD, ${ }^{3}$ \\ Annette M. Molinaro, PhD, ${ }^{3,4}$ Joseph L. Wiemels, PhD, ${ }^{4}$ Joellen M. Schildkraut, PhD, ${ }^{5}$ \\ Melissa L. Bondy, PhD, ${ }^{6}$ Mitchel Berger, MD, ${ }^{3}$ Robert Jenkins, MD, PhD, ${ }^{7}$ \\ and Margaret Wrensch, $\mathrm{PhD}^{3,4}$
}

'School of Public Health, Yale University, New Haven, Connecticut; '2Department of Neurosurgery, Brigham and Women's Hospital, Boston, Massachusetts; Departments of ${ }^{3}$ Neurological Surgery, and ${ }^{4} E$ pidemiology and Biostatistics, University of California at San Francisco School of Medicine, San Francisco, California; ${ }^{5}$ Department of Community and Family Medicine, Duke University School of Medicine, Durham, North Carolina; ${ }^{6}$ Department of Epidemiology, Baylor College of Medicine, Houston, Texas; and 'Department of Pathology, Mayo Clinic, Rochester, Minnesota

Significant gaps exist in our understanding of the causes and clinical management of glioma. One of the biggest gaps is how best to manage low-grade (World Health Organization [WHO] Grade II) glioma. Low-grade glioma (LGG) is a uniformly fatal disease of young adults (mean age 41 years), with survival averaging approximately 7 years. Although LGG patients have better survival than patients with high-grade (WHO Grade III or IV) glioma, all LGGs eventually progress to high-grade glioma and death. Data from the Surveillance, Epidemiology and End Results (SEER) program of the National Cancer Institute suggest that for the majority of LGG patients, overall survival has not significantly improved over the past 3 decades, highlighting the need for intensified study of this tumor. Recently published research suggests that historically used clinical variables are not sufficient (and are likely inferior) prognostic and predictive indicators relative to information provided by recently discovered tumor markers (e.g., 1p/19q deletion and IDH1 or IDH2 mutation status), tumor expression profiles (e.g., the proneural profile) and/or constitutive genotype (e.g., rs55705857 on 8q24.21). Discovery of such tumor and constitutive variation may identify variables needed to improve randomization in clinical trials as well as identify patients more sensitive to current treatments and targets for improved treatment in the future. This article reports on survival trends for patients diagnosed with LGG within the United States from 1973 through 2011 and reviews the emerging role of tumor and constitutive genetics in refining risk stratification, defining targeted therapy, and improving survival for this group of relatively young patients.

http://thejns.org/doi/abs/10.3171/2014.10.FOCUS12367

KEY WORDS glioma; low grade; survival; SEER; epidemiology; genes; GWAS; treatment

$\mathrm{G}$ LIOMAS are classified as Grades I to IV based on histology and clinical criteria. ${ }^{43}$ Grade I tumors are generally benign and frequently curable with complete resection, occur primarily in children, and are believed to represent an entity separate from Grade II-IV tumors (seen primarily in adults). Adult Grade II tumors (low-grade gliomas [LGGs]) include: 1) astrocytomas, 2) oligo-astrocytomas or mixed gliomas, and 3) oligodendrogliomas. ${ }^{43}$ Astrocytomas and oligodendrogliomas con- sist of astrocytes or oligodendrocytes, respectively, while mixed gliomas contain a mixture of the 2 cell types. Essentially all Grade II lesions eventually progress to highgrade glioma (HGG) (Grade III/IV). Grade IV tumors (also known as glioblastomas [GBMs]) that arise from LGGs are termed "secondary GBM" to differentiate them from "primary" or "de novo" GBM, as the pathway leading to these 2 GBM types differs in a number of genetic abnormalities and clinical characteristics. ${ }^{74}$ Most patients

ABBREVIATIONS GBM = glioblastoma; GWAS = genome-wide association study; HGG = high-grade glioma; LGG = low-grade glioma; MDA = MD Anderson Center; MGMT = $0^{6}$-methylguanine-DNA methyltransferase; PCV = procarbazine, CCNU, and vincristine; RCT = randomized clinical trial; SEER = Surveillance, Epidemiology, and End Results; SNP = single-nucleotide polymorphism; TCGA = The Cancer Genome Atlas; TMZ = temozolamide; UCSF = University of California, San Francisco. SUBMITTED October 31, 2012. ACCEPTED October 16, 2014. INCLUDE WHEN CITING DOI: 10.3171/2014.10.FOCUS12367.

DISCLOSURE This work was supported by NIH Grant R01 CA119215. Work at UCSF was supported by the NIH (grant numbers R25CA112355, R01CA52689, R01CA126831, and P50CA097257), as well as the National Brain Tumor Foundation, and the UCSF Lewis Chair in Brain Tumor Research. 
initially undergo resection/biopsy at the time of diagnosis and then radiation therapy and/or treatment with the single chemotherapeutic agent temozolamide (TMZ) at some point. However, many of these relatively uniformly treated patients advance more quickly than others to recurrence and death. Variation in the few known prognostic factors (most of which are themselves highly correlated)-e.g., age, performance status, tumor size/ location, extent of resection, and histological subtypedoes not adequately explain the progression and survival differences in these patients. To date, the detection of treatment effect is limited. Gross-total resection appears associated with better survival for patients able to undergo such a procedure but has never been and is unlikely to be assessed in randomized clinical trials (RCTs); ;13,30,59 the improvement may be due to biases from differential tumor aggressiveness in nonresectable versus resectable portions of the brain and from clinician predictions of the patients likely to benefit most from resection. Randomized clinical trials suggest that radiation therapy prolongs time to recurrence but not overall survival ${ }^{36,38,62,72}$ and may be associated with reduction in quality of life and cognition, $1,16,38,45$ while the impact of TMZ, the primary single chemotherapeutic agent now used to treat LGG, has shown benefit primarily in RCTs of HGG but has not been fully assessed in LGG. $., 37,50,54,68,70$ For LGG, no RCT has compared TMZ (which is associated with blood disorders and leukemia ${ }^{41}$ to other agents (trials are ongoing that compare TMZ to radiation therapy as well as the combination of TMZ and radiation therapy to radiation therapy without TMZ). A recently updated trial (RTOG 9802) comparing radiation therapy with or without procarbazine, $\mathrm{CCNU}$, and vincristine (PCV) reports improved progression-free as well as overall survival with the addition of PCV, but ironically this combination has been infrequently used over the past decade to treat LGG. ${ }^{6,63}$ There is no comprehensive clinical prognostic or predictive classification for LGG that combines information on histology, tumor markers and constitutive/tumor genotype, and surgical treatment relative to outcome, and this has led to confusion over how to best manage these patients. The goal of this review is to examine population-based survival rates for patients with LGG within the United States by standard patient demographics and initial treatment and to then review emerging data on patient and tumor genotype relative to survival after a diagnosis of LGG.

\section{Methods}

We examined data from the Surveillance, Epidemiology, and End Results (SEER) Program of the National Cancer Institute from 1973 through 2011 (http://seer.cancer. gov/data/) that reflect cases involving 2825 patients diagnosed between the ages of 20 and 79 years with a histologically confirmed Grade II supratentorial (topography codes C71.0-71.4) glioma (morphology codes: mixed glioma [ICD-0 9382], oligodendroglioma [ICD-0 9450], or astrocytoma [ICD-0 9400]). In an effort to examine a homogeneous study population and to reduce the probability of including individuals with metastatic lesions, individuals with more than 1 primary cancer (i.e., a glioma and a cancer of another site) were excluded from these analyses, as were patients diagnosed at death (autopsy only).

In addition to topography and morphology, information on patient sex, race, age, and year of diagnosis were available, as was information regarding whether the patient had been treated with resection (yes/no), radiation therapy (yes/no), or chemotherapy (yes/no) as part of the first course of treatment. Treatment parameters after the first course are not available in these data, nor are specifics of chemotherapy regimes. Race was defined according to SEER categories of white, black, and other, due to small sample sizes in the non-black, non-white categories. Age was used as a continuous variable in the proportional hazards model. The primary outcome variable was time to death as measured in years.

Comparison of cases by descriptor variables was done using a chi-square or Fisher's exact test for discrete variables and a t-test for continuous variables. Estimates of survival probabilities (with 95\% confidence intervals) were calculated using Kaplan-Meier product limit methodology and compared using a Wilcoxon log-rank test. Hazard rates were computed using a Cox proportional hazards model..$^{18}$ All analyses were completed using the SAS statistical software package version 9.3.

\section{Results}

Descriptive statistics for the sample are presented in Table 1. The majority (51.6\%) of the cases are classified as astrocytoma, with $33.5 \%$ classified as oligodendroglioma and $14.9 \%$ as mixed glioma. The reported distributions of these 3 tumor types has changed significantly over time ( $p$ $<0.001$ ), with fewer cases being classified as astrocytoma and more being identified as either oligodendroglioma or mixed glioma. ${ }^{21}$ The majority of patients were male $(58.9 \%)$ and white $(89.1 \%)$. The mean age at diagnosis was 41.4 (SD 15.6) years and did not vary by sex, race, or year of diagnosis. Persons with mixed glioma were diagnosed on average 2 years earlier than patients with other pathology. Treatment data, which include only the first course, show that the majority of LGG patients received only resection at first course; only $3.7 \%$ received chemotherapy as part of the initial treatment and the use of radiation at first course declined over time. Initial treatment did not vary by sex or race but did differ by age, with younger patients more likely to undergo resection. Treatment differed by location of the lesion (which did not vary by sex or race). As would be expected, individuals with parietal lobe lesions were more likely to receive radiation therapy and less likely to receive resection than were patients with lesions located elsewhere in the brain.

The median duration of survival for patients with astrocytoma, mixed glioma, and oligodendroglioma was $5.2,5.6$, and 7.2 years, respectively, with younger age at onset associated with an improved prognosis and use of radiation therapy at initial treatment associated with a less favorable prognosis across all 3 histological subtypes. Approximately $20 \%$ of patients survived for at least 2 decades. Female sex was associated with improved prognosis for patients with astrocytoma but not for persons di- 
TABLE 1. Number of diagnoses (and deaths) for adult supratentorial LGG by histological subgroup (SEER data, 1973-2011)

\begin{tabular}{ccccc}
\hline Variable & Astrocytoma & Oligodendroglioma & Mixed Glioma & Total \\
\hline Age $($ yrs $)$ & & & & \\
\hline $20-39$ & $732(442)$ & $445(153)$ & $229(83)$ & $1406(678)$ \\
\hline $40-59$ & $538(392)$ & $421(248)$ & $31(20)$ & $1120(616)$ \\
\hline $60+$ & $188(162)$ & $80(56)$ & & $299(238)$ \\
\hline Race & & & $374(150)$ & $2518(1366)$ \\
\hline White & $1295(889)$ & $849(317)$ & $18(8)$ & $142(91)$ \\
\hline Black & $92(70)$ & $32(13)$ & $29(11)$ & $165(75)$ \\
\hline Other & $71(37)$ & $65(27)$ & $185(69)$ & $1665(931)$ \\
\hline Sex & & & $236(100)$ & $1591)$ \\
\hline Female & $591(391)$ & $384(131)$ & & $3(3)$ \\
\hline Male & $867(605)$ & $562(226)$ & $36(28)$ & $478(422)$ \\
\hline Year of diagnosis & & & $92(64)$ & $705(470)$ \\
\hline $1973-1979$ & $143(133)$ & $7(7)$ & $263(74)$ & $1377(482)$ \\
\hline $1980-1989$ & $414(370)$ & $28(24)$ & $27(0)$ & $112(5)$ \\
\hline $1990-1999$ & $346(252)$ & $267(154)$ & & \\
\hline $2000-2009$ & $520(1237)$ & $594(171)$ & $59(1)$ & \\
\hline $2010-2011$ & $36(4)$ & & & \\
\hline
\end{tabular}

agnosed with mixed glioma or oligodendroglioma. After controlling for race (white vs nonwhite), age at onset, sex, and initial course of treatment (surgery yes/no, radiation yes/no), there was no improvement in overall survival over time (defined as year of diagnosis before year 2000 vs diagnosis on or after the year 2000) for patients diagnosed with oligodendroglioma (HR $1.08,95 \%$ CI $0.85-1.4$ ), astrocytoma (HR $0.98,95 \%$ CI $0.83-1.15$ ), or mixed glioma (HR 0.76, 95\% CI 0.54-1.07) (Figs. 1-3). Interestingly, when the time cutpoint is placed at 2005 rather than at
2000, the results are similar for astrocytoma and oligodendroglioma, but persons diagnosed with mixed glioma on or after 2005 show improved survival compared with those diagnosed prior to 2005 .

\section{Discussion}

The general lack of improvement in survival for LGG patients over the past 3 decades points to the need for an intensified focus on these tumors. As for HGG, several intriguing findings have emerged, many over just the past

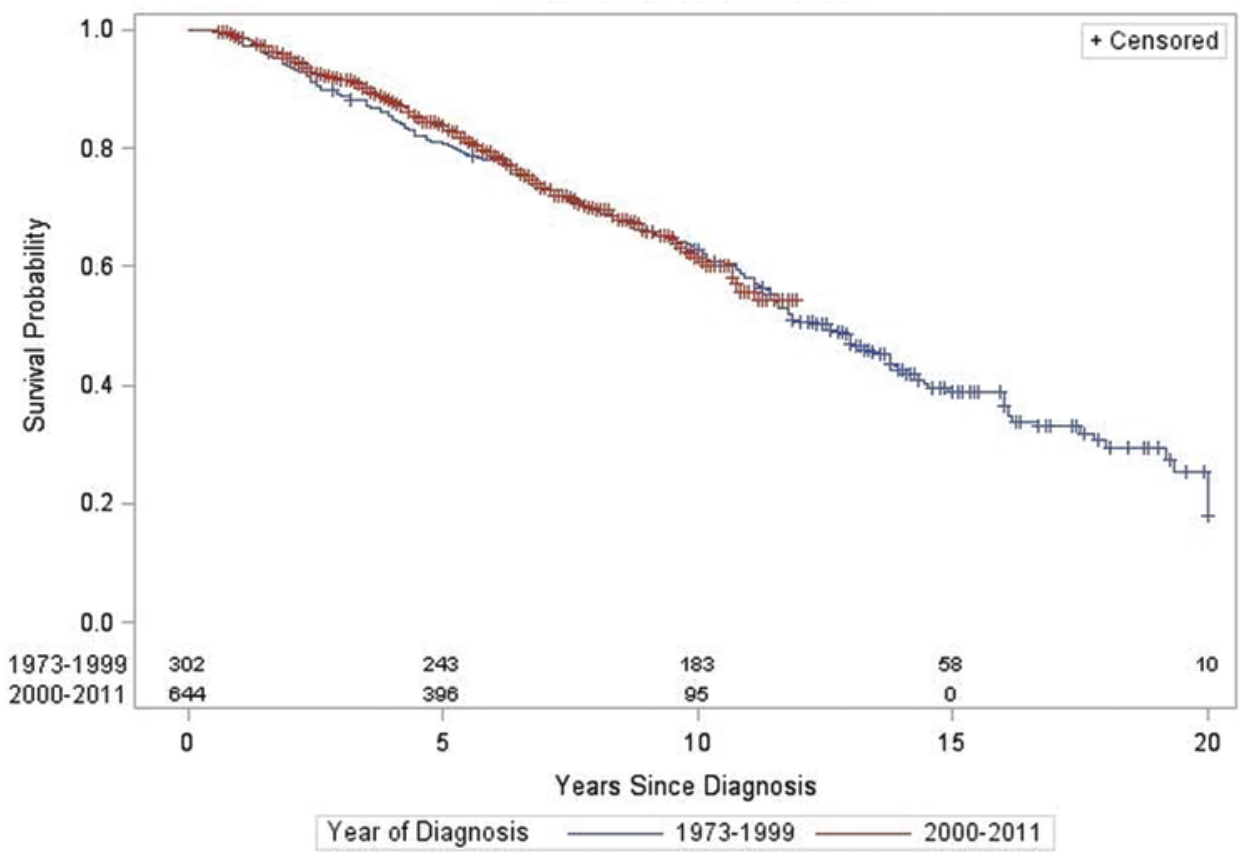

FIG. 1. Survival by year of diagnosis for patients with oligodendroglioma (SEER 1973-2011). 


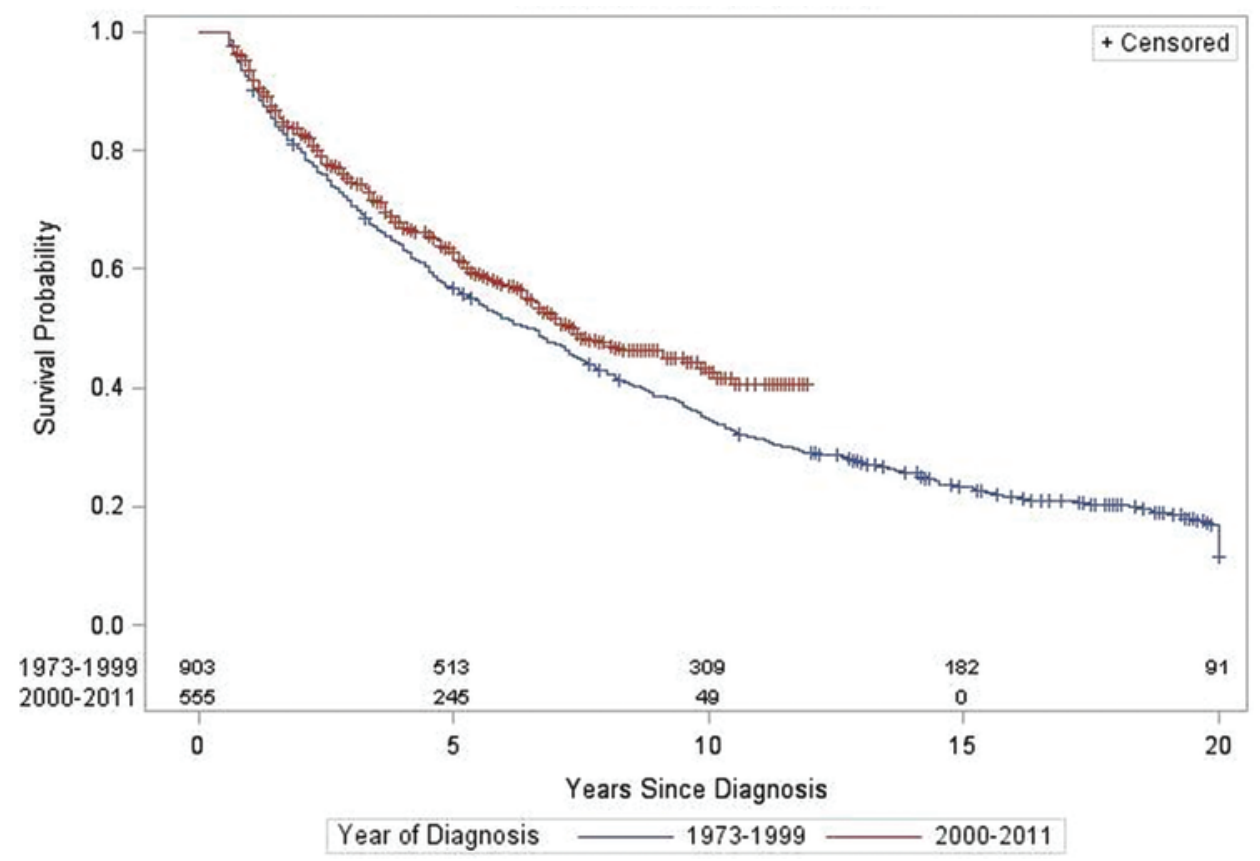

FIG. 2. Survival by year of diagnosis for patients with astrocytoma (SEER 1973-2011).

year or two, with respect to molecular tumor markers, gene expression, and constitutive genotype.

\section{Molecular Tumor Markers}

A number of molecular tumor markers have been associated with overall survival for patients with LGG, including 1) combined deletions of chromosomes $1 \mathrm{p}$ and $19 \mathrm{q},{ }^{28,31}$ 2) mutations in the isocitrate dehydrogenase 1 and 2 (IDH1 and IDH2) genes, ${ }^{28,80}$ and 3) methylation of the $\mathrm{O}^{6}$-methylguanine-DNA methyltransferase (MGMT) gene. ${ }^{28}$ The high rate of $p 53$ mutation or deletion in some gliomas, as well as the belief that this change represents an early step in glioma development, has led investigators to examine this alteration in association with LGG survival, with inconsistent results. ${ }^{21,26,28}$

\section{Codeletion of $1 p$ and $19 q$}

Although deletion of $1 p$ and/or $19 q$ occurs in all LGG subtypes, these chromosome arms are deleted in $40 \%-$ $90 \%$ of Grade II oligodendrogliomas, and their deletion

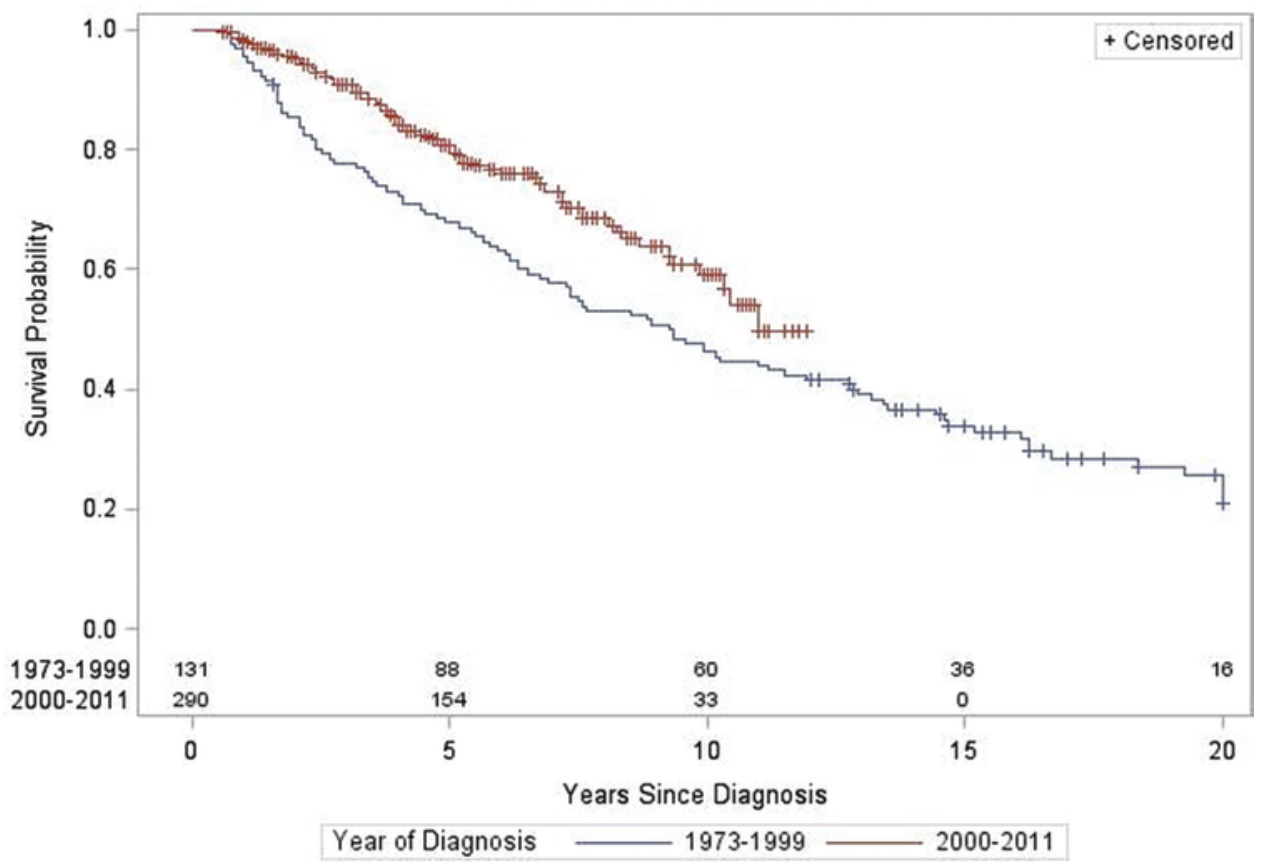

FIG. 3. Survival by year of diagnosis for patients with mixed glioma (SEER 1973-2011). 
is associated with increased survival as well as treatment sensitivity. ${ }^{31,35}$ The mechanism by which $1 \mathrm{p} / 19 \mathrm{q}$ loss affects outcome and response is unknown, with no gene on either arm clearly defined as responsible. Recent sequencing revealed mutations in 2 tumor suppressor genes: homolog of Drosophilia capicua $(C I C)$ on $19 \mathrm{q}$ and farupstream binding protein 1 (FUBPI) on $1 \mathrm{p}$ in $38 \%$ and $14 \%$ of 21 Grade II oligodendrogliomas (and 0 [0\%] of 15 Grade II astrocytomas and 1 [6\%] of 18 Grade II mixed gliomas). ${ }^{34}$ Essentially all gliomas with a $C I C$ or $F U B P I$ mutation in that study ${ }^{34}$ also had an $I D H$ gene mutation as well as codeletion of $1 p$ and $19 q$. Jenkins et al. ${ }^{31}$ found that most $1 \mathrm{p}$ and $19 \mathrm{q}$ deletions in Grade II oligodendrogliomas were the result of an unbalanced translocation between the whole chromosomal arms of $1 \mathrm{p}$ and $19 \mathrm{q}$ and that translocation/deletion was associated with significantly improved overall survival.

\section{IDH1 and IDH2}

A recent notable finding is that mutations in the $\mathrm{NADP}^{+}$ (nicotinamide adenine dinucleotide phosphate)-dependent isocitrate dehydrogenases encoded by IDHI and IDH2 occur in the majority of Grade II gliomas (all subtypes) and Grade III gliomas as well as secondary GBMs but in only a minority of primary GBMs. ${ }^{51,83}$ Isocitrate dehydrogenase 1 is an enzyme that catalyzes the oxidative decarboxylation of isocitrate to alpha-ketoglutarate, leading to NADPH (reduced form of NADP ${ }^{+}$) production, and it is thought to play a role in cellular protection from oxidative stress. IDH mutations are associated with a glioma $\mathrm{CpG}$ island DNA hypermethylator phenotype (G-CIMP) ${ }^{71}$ and with improved LGG survival ${ }^{80}$ as well as possible LGG response to treatment. ${ }^{26,28}$ Such data suggest that $I D H$ mutations represent an early step in the development of LGG. ${ }^{44}$

\section{MGMT}

Methylation of MGMT (a DNA repair gene located on $10 q)$ is a commonly observed change in $\mathrm{LGG}^{26}$ that predicts HGG response to treatment as well as overall surviv$\mathrm{al}^{8,27}$ this change may confer chemosensitivity in $\mathrm{LGG}^{26,28}$ by causing an altered response to TMZ (the primary agent used to treat LGG), although efforts to examine this are limited by small sample size..$^{26,28}$

\section{TP53}

There is evidence to suggest that a series of ordered genetic alterations occurs in progression from LGG to HGG, with TP53 mutation being an early event. ${ }^{80}$ TP53 is the most frequently mutated gene in GBM, and its mutation is a common event in The Cancer Genome Atlas (TCGA) proneural GBM subtype (believed to include the majority of LGGs that progressed to HGG). TP53 mutation is found in all LGG subtype ${ }^{26}$ but is highly correlated with the proportion of tumor astrocytes. Interestingly, a recent study ${ }^{34}$ examined mutations in the chromatin modifier alpha thalassemia/mental retardation syndrome $X$-linked (ATRX) (as well as CIC, FUBPI, and IDHI) and noted almost complete correlation between the presence of TP53 and ATRX mutations, regardless of LGG subtype.

The extent to which any of these markers are merely indicators of the natural progression of disease or of treatment sensitivity (or both) remains ill defined. In some instances (i.e., $1 \mathrm{p}$ and $19 \mathrm{q}$ codeletion and oligodendroglioma histology), a marker and a subtype are correlated, leading to confusion about whether it is the marker or the subtype (or both) that is associated with outcome. ${ }^{26}$ Similarly, correlation exists between markers (i.e., IDHI mutation and $1 \mathrm{p}$ and $19 \mathrm{q}$ deletion). ${ }^{28}$ Adding to the confusion is the dynamic classification process of LGG subtype, with changes in the relative reported proportions of these subtypes over time reflecting an increasing awareness of the subtleties of histopathological classification for this group of tumors. ${ }^{12,43}$ Researchers have started to elucidate the relative roles of histology and the aforementioned markers both before treatment (thus capturing factors associated with prognosis) and after treatment (capturing factors associated with prediction). Several small studies suggest that response to $\mathrm{TMZ}^{39}$ and progression-free survival ${ }^{23}$ are associated with $1 \mathrm{p}$ deletion ${ }^{39}$ and low $M G M T$ protein expression, ${ }^{23,39}$ but all of these studies had a sample size of less than 70, primarily focused on Grade II oligodendrogliomas, and did not examine overall survival. Recently, several groups have presented results from larger case series. Using 271 LGGs drawn from the Groupe Hospitalier Pitié-Salpêtrière in Paris, Houillier et al. ${ }^{28}$ tested whether TP53 mutation, $1 \mathrm{p} / 19 \mathrm{q}$ codeletion, MGMT promoter methylation, and IDHI mutation predicted natural course of disease or response to treatment with TMZ at the time of diagnosis while controlling for extent of resection. In multivariate analyses, only performance status and resection (but neither histology nor marker) was predictive of progression-free survival in the 171 untreated patients. In the 74 evaluable patients treated upfront with TMZ, IDH1 mutation, $1 \mathrm{p} / 19 \mathrm{q}$ codeletion, and MGMT promoter methylation were each associated in univariate analyses with response to TMZ, but small sample size precluded a multivariate analysis including the 3 markers simultaneously and did not allow for evaluation of overall survival. Hartmann et al. ${ }^{26}$ performed a similar analysis on data from 139 LGG patients from the German Cancer Network. Again no marker was prognostic in patients who did not receive chemotherapy or radiation therapy. IDHI mutation and $1 p$ and $19 q$ codeletion were predictive of overall survival (and of progression-free survival in persons receiving treatment at diagnosis). As noted by the authors of both studies, insufficient sample size did not allow for examination of these markers by histological subtype.

\section{Tumor Gene Expression}

Recent HGG analyses from TCGA (http://cancer genome.nih.gov) have used several different technology platforms, including mutation arrays, copy number arrays, expression arrays, and methylation arrays., ${ }^{9,52,74}$ Analysis of expression array data has identified molecular subtypes associated with grade and outcome and has shown that expression profiles are better predictors of outcome than histological subtype., ${ }^{9,14,52,74}$ The TCGA and other research groups ${ }^{9,24,52,74}$ have recently defined and validated 4 gene-expression-based classification profiles for Grade IV glioma (GBM): 1) proneural (notable for PDGFRA alterations, IDH1 and TP53 mutations, as well as oligodendro- 
glioma cell type), 2) neural (associated with a variety of neuron markers and closest to normal brain), 3) classical (EGFR amplification and $C D K N 2 A$ alterations), and 4) mesenchymal (NF1 and MET alterations). Although this classification system was constructed using only GBM tumors, intriguing findings relative to LGG are noted: 1) the proneural profile included 3 of the 4 known secondary GBMs (believed to arise from LGG), and 2) as previously noted for LGG patients, the proneural profile was notable for young age at onset as well as longer survival, particularly when Grade II and III gliomas from validation sets were added. The absence of LGG in the TCGA data led 2 groups ${ }^{15,25}$ to examine the predictive value of the TCGA profiles specifically for LGG. Both groups ${ }^{15,25}$ used Affymetrix gene expression data for a small set of LGGs (65 Grade II astrocytomas, 4 Grade II mixed gliomas, and 30 Grade II oligodendrogliomas) from the Repository for Molecular Brain Neoplasia Data (REMBRANDT) and reported similar findings, with the TCGA profiles associated with prognostic value for LGG. ${ }^{15}$ More recently, the TCGA analyzed 293 "lower grade gliomas" (Grades II and III). Despite using a wide range of sophisticated technology platforms, the final results suggested that lower-grade tumors can be simply and better characterized solely by 2 tumor markers, $I D H 1 / 2$ and $1 \mathrm{p} / 19 \mathrm{q}$ deletion status, than by the traditionally used histology and grade. ${ }^{75}$ The findings are considered paradigm breaking and suggest that the decades-long classification system for glioma (focused on histology and grade) is likely inferior to a new more molecularly based (but clinically simple and cost efficient) classification scheme. With respect to outcome, these molecular findings remain untested in a pure LGG cohort and uncorrected for an additional variable of clinical import, extent of resection. ${ }^{13,53}$

\section{Constitutive Genetic Polymorphisms}

\section{Glioma Risk}

Genetic polymorphisms identified in association with glioma incidence are clearly of interest when considering genes associated with glioma survival., 2,3,10,17,19,20,22, 29,47,48,55-57,61,84 An emerging theme in glioma research has been that the genes and pathways identified in linkage and tumor studies are also being identified in genome-wide association studies (GWASs). This demonstrates that, in addition to the rare variations associated with Mendelian disorders ${ }^{46}$ common genetic variations also contribute to gliomagenesis. While rare heritable loss-of-function mutations in TP53 and p16 cause glioma-associated familial cancer syndromes, inherited single-nucleotide polymorphisms (SNPs) near both these genes also appear to contribute to gliomagenesis. In total, GWAS of glioma patients has identified 9 independently significant SNP associations located in 8 genes (Table 2). ${ }^{32,33,60,64,66,76-78}$ The first two glioma GWASs, ${ }^{64,79}$ one of which included only HGG (from University of California, San Francisco [UCSF]/ Mayo) ${ }^{78}$ and the other (from the MD Anderson Center [MDA] $)^{64}$ included HGG and some LGG, confirmed glioma risk loci in or near TERT (5p15), CDKN2A/B (9p21) (a gene region harboring p16, a tumor suppressor gene often homozygously deleted in GBM), and RTEL1 (20q13). The MDA GWAS, ${ }^{64}$ which included LGG cases, identified 2 additional loci: CCDC26 (8q24) and PHLDB1 (11q23). The top 13 SNPs in these 5 regions were further investigated by tumor subtype in 1446 cases and 1134 controls from UCSF/Mayo (with 224 Grade II/III oligodendrogliomas, 166 Grade II/III mixed gliomas, and 103 Grade II [only] astrocytomas). ${ }^{32}$ As reported in the MDA GWAS, 64 $C C D C 26$ (8q24) region loci were associated with Grade II/III oligodendroglioma $\left(\mathrm{OR}=2.05, \mathrm{p}=8.3 \times 10^{-11}\right)$ but not GBM (Grade IV) risk, with association with Grade II/ II oligodendroglioma seen regardless of $1 \mathrm{p} / 19 \mathrm{q}$ deletion status (although the greatest risk was seen with codeletion present). In contrast, $R T E L$ region polymorphisms were most strongly associated with Grade IV but less so with Grade II/III glioma risk. The TERT region was associated with all grades and types of glioma. The $C D K N 2 A / B$ region SNPs were also associated with Grade IV and Grade II/III astrocytoma but not with Grade II/III oligodendroglioma. Insufficient data were available to draw conclusions about Grade II astrocytoma and Grade II oligodendroglioma independent of Grade III oligodendroglioma or about Grade II versus Grade III mixed glioma. A similar analysis was performed in the German and French replication cohorts of the MDA GWAS, again showing that $C C D C 26$ and PHLDB1 loci were inversely and RTEL1 and TERT loci were positively correlated with grade. ${ }^{66}$ Data from a Chinese population agree as well. ${ }^{10} \mathrm{~A}$ pooled analysis of the US/United Kingdom/German/French data confirmed these findings and found evidence of an additional independent association for glioma (regardless of grade) risk with rs11979158 and rs2252586 at 7p11.2, which encompasses the EGFR gene, although interestingly this gene was not associated with survival. ${ }^{60}$ The results listed above are remarkably confirmatory (in an era where GWAS results may vary widely) and strongly suggest that distinct germline polymorphisms underlie different glioma subtypes (i.e., $C C D C 26$ and $P H L D B 1$ loci are consistently associated with LGG while other loci are either primarily associated with HGG or with all glioma regardless of grade and histology). Jenkins et al. ${ }^{33}$ further examined the $C C D C 26(8 \mathrm{q} 24)$ region and found strong association for a low-frequency variant at 8q24.21 (rs55705857) associated with 1) Grade II/III oligodendroglioma regardless of $I D H$ mutation status (OR 6.3, p = 2.2 $\times 10^{-23}$ ), and 2) Grade II-IV astrocytoma with mutated IDH1/IDH2 (OR $5.16-6.66, \mathrm{p}=4.7 \times 10^{-12}$ to $2.2 \times 10^{-8}$ ) but not astrocytic tumors with wildtype IDH1/IDH2. Their LGG-specific findings are remarkable, with increasing risk associated with decreasing astrocyte involvement $\left(\mathrm{OR}_{\text {astroII }} 3.82,95 \%\right.$ CI 2.63-5.54, p = $1.7 \times 10^{-12} ; \mathrm{OR}_{\text {mixedII }} 5.01,95 \%$ CI 3.48$7.21, \mathrm{p}=3.7 \times 10^{-18}$; and $\mathrm{OR}_{\text {oligoII }} 7.06,95 \% \mathrm{CI} 5.10-9.77, \mathrm{p}$ $\left.=6.2 \times 10^{-32}\right)$. Two new reports ${ }^{58,75}$ are also of note: Using existing as well as new data from the UCSF and Mayo groups, Rice et al. ${ }^{58}$ showed that the PHLDBI SNP is associated strictly with $I D H$-mutated gliomas, while Walsh et al. ${ }^{75}$ replicated the findings that $C D K N 2 B$ SNPs are associated with low-grade astrocytomas. In summary, 4 of the above-mentioned genes appear to contribute to the development of all glioma grades and histological types (RTEL, TERT, EGFR, TP53), whereas the other 3 genes appear to contribute only to the development of certain glioma subtypes (Table 2). CCDC26 variants increase 
TABLE 2. Glioma-associated susceptibility variants detected by GWAS and fine-mapping

\begin{tabular}{lccccc}
\hline $\begin{array}{c}\text { Candidate Gene } \\
\text { (chromosome location) }\end{array}$ & Risk Allele & $\begin{array}{c}\text { Magnitude of } \\
\text { Association* }\end{array}$ & $\begin{array}{c}\text { Risk Allele } \\
\text { Frequency }\end{array}$ & Putative Functional Significance & Associated Glioma Subtypes \\
\hline TERC (3q26.2) & rs1920116-G & + & 0.72 & Increased telomere length & HGG \\
\hline TERT (5p15.33) & rs2736100-C & + & 0.51 & Increased telomere length & All glioma subtypes \\
\hline EGFR (7p11.2) & rs2252586-A & + & 0.27 & Unknown & All glioma subtypes \\
\hline EGFR (7p11.2) & rs11979158-A & + & 0.82 & Unknown & All glioma subtypes \\
\hline CCDC26 (8q24.21) & rs55705857-G & +++ & 0.046 & microRNA site & Oligodendroglial tumors \& IDH- \\
& & & & & mutated astrocytic tumors \\
\hline CDKN2B/ANRIL (9p21.3) & rs1412829-G & + & 0.43 & Unknown & Astrocytic tumors of all grades \\
\hline PHLDB1 (11q23.3) & rs498872-A & + & 0.31 & Unknown & IDH-mutated gliomas \\
\hline TP53 (17p13.1) & rs78378222-C & ++ & 0.014 & Alteration of polyadenylation signal & All glioma subtypes \\
& & & & impairs TP53 mRNA processing & All glioma subtypes \\
\hline RTEL1 (20q13.33) & rs6010620-G & + & 0.76 & Unknown &
\end{tabular}

* Magnitude of Association: +++ represents OR $\geq 5.0$, ++ represents $2.0 \leq \mathrm{OR}<5.0$, and + represents $1.0<\mathrm{OR}<2.0$.

$\dagger$ Allele frequency in Caucasians, extracted from HapMap CEPH (Centre d'Etude du Polymorphisme Humain) data where available.

the risk for oligodendroglial tumors regardless of $I D H$ mutation status and also for $I D H$-mutated astrocytoma. SNPs near CDKN2B/ANRIL confer increased risk for astrocytic tumors of all grades, including GBM, but are not associated with oligodendroglial tumors. The histological specificity of these SNP associations remains an area of active research.

\section{Glioma Outcome}

There are few studies of genetic polymorphism and survival after diagnosis of glioma; those that exist focus on HGG (no study includes more than 50 LGG patients) with examination of SNPs in genes involved in DNA repair, cell cycle regulation, and immune function as well as in tumor markers of note. ${ }^{4,21,40,49,67,69,73,78,82}$

Genome-Wide Association Studies. No data exist specific to LGG, but several informative efforts have been undertaken relative to HGG by Dr. Wrensch's group, which performed the first GBM GWAS survival analy$\mathrm{sis}^{80,81}$ in uniformly treated patients (treated with surgery, radiation therapy, and TMZ) and found that SSBP2 (a single-stranded DNA binding protein on 5q14.1) germline variants were associated with survival (discovery [UCSF] and validation [Mayo, GliomaSE, and TCGA] sets show a combined $\mathrm{HR}_{\mathrm{rs} 7732320}$ of $1.64,95 \%$ CI $1.34-2.00, \mathrm{p}=1.3 \times$ $10^{-6}$ ) and that expression of SSBP2 in GBMs was significantly related to reduced survival (HR 1.22, 95\% CI 1.09$1.36, \mathrm{p}=5.3 \times 10^{-4}$ ). Interestingly, among TCGA and other GBM patients, SSBP2 expression was highest among patients with the proneural signature, a group likely to include persons with secondary GBM (i.e., progressed from LGG), suggesting that SSBP2 germline variants and tumor expression (which were not linked to $I D H$ mutation status) may be important independent predictors of survival for patients with LGG. Dr. Bondy also examined associations with GBM survival with the 100 top-ranking glioma susceptibility polymorphisms identified from the 2 glioma GWASs ${ }^{64,79}$ and found that polymorphisms in the LIG4, HMGA2, BTBD2, and RTEL1 genes (all involved in the double-strand break repair pathway) were associated with GBM survival in the MDA GWAS cohort (although not confirmed in the validation set). ${ }^{42}$ Preliminary analyses from the UCSF/Mayo study indicate that the variant at 8q24.21 (rs55705857) associated so strongly with glioma risk appears to also be associated with survival.

The data used here to estimate survival are taken from the SEER program (http://seer.cancer.gov/data/). Although an important description of "real-world" LGG practice that includes persons of all ages, races, and medical status, the data are limited by 1) a lack of a uniform histological review, 2) treatment data that are restricted to first course (hence data on radiation therapy and chemotherapy are limited or absent) and not adjusted for clinical factors likely to influence treatment assignment, and 3) no information on constitutive/tumor genotype, tumor markers, or patient comorbidities.

One important reason for the lack of knowledge concerning LGG is that these patients are generally only included as a convenience subsample in studies of HGG with results driven by the much larger numbers of HGGs in these studies. ${ }^{9,11,32,60,64,65,79}$ Furthermore, the lack of effect in randomized clinical trials is likely also due in part to the unknowing inclusion of genetically dissimilar tumors into one study arm. In the future, clarification of the tumor markers/profiles known to be associated with outcome (both natural progression as well as response to treatment) will be required to be measured in any planned RCT to preserve randomization. The import of such markers and profiles is already recognized by organizers of the HGG trials with tumor materials retrospectively being analyzed to assess randomization. As LGG represents the first step in a multistage disease process, the need to focus efforts at the start of the disease process is clear. Large sample cohorts, which will likely require the development of consortia given the relatively small numbers of these tumors, will be necessary. As can be seen from the literature morphological and molecular subtyping is critical to cancer genetic epidemiology ${ }^{33}$ and to date not explored specifically for LGG. Discovery of genes associated with poor outcomes will allow for improvement of randomization schemes in clinical trials of LGG as well as suggest novel biological 
mechanisms for development of targeted therapy designed to improve survival. The time is right for researchers to take advantage of emerging genetic technology, statistical methodology, and computing capability to create a new clinical paradigm for LGG.

\section{References}

1. Aaronson NK, Taphoorn MJ, Heimans JJ, Postma TJ, Gundy CM, Beute GN, et al: Compromised health-related quality of life in patients with low-grade glioma. J Clin Oncol 29:4430-4435, 2011

2. Bethke L, Sullivan K, Webb E, Murray A, Schoemaker M, Auvinen A, et al: The common D302H variant of CASP8 is associated with risk of glioma. Cancer Epidemiol Biomarkers Prev 17:987-989, 2008

3. Bethke L, Webb E, Murray A, Schoemaker M, Johansen C, Christensen HC, et al: Comprehensive analysis of the role of DNA repair gene polymorphisms on risk of glioma. Hum Mol Genet 17:800-805, 2008

4. Bhowmick DA, Zhuang Z, Wait SD, Weil RJ: A functional polymorphism in the EGF gene is found with increased frequency in glioblastoma multiforme patients and is associated with more aggressive disease. Cancer Res 64:1220-1223, 2004

5. Brada M, Viviers L, Abson C, Hines F, Britton J, Ashley S, et al: Phase II study of primary temozolomide chemotherapy in patients with WHO grade II gliomas. Ann Oncol 14:17151721,2003

6. Buckner JC, Pugh SL, Shaw EG, Gilbert MR, Barger G, Coons S, et al: Phase III study of radiation therapy (RT) with or without procarbazine, $\mathrm{CCNU}$, and vincristine (PCV) in low-grade glioma: RTOG 9802 with Alliance, ECOG, and SWOG. J Clin Oncol 32:5s, 2014 (Abstract)

7. Caggana M, Kilgallen J, Conroy JM, Wiencke JK, Kelsey KT, Miike R, et al: Associations between ERCC2 polymorphisms and gliomas. Cancer Epidemiol Biomarkers Prev 10:355-360, 2001

8. Cairncross JG, Ueki K, Zlatescu MC, Lisle DK, Finkelstein DM, Hammond RR, et al: Specific predictors of chemotherapeutic response and survival in patients with anaplastic oligodendrogliomas. J Natl Cancer Inst 90:1473-1479, 1998

9. Cancer Genome Atlas Research Network: Comprehensive genomic characterization defines human glioblastoma genes and core pathways. Nature 455:1061-1068, 2008

10. Carpentier C, Laigle-Donadey F, Marie Y, Auger N, Benouaich-Amiel A, Lejeune J, et al: Polymorphism in Sp1 recognition site of the EGF receptor gene promoter and risk of glioblastoma. Neurology 67:872-874, 2006

11. Chen H, Chen Y, Zhao Y, Fan W, Zhou K, Liu Y, et al: Association of sequence variants on chromosomes 20,11 , and 5 (20q13.33, 11q23.3, and 5p15.33) with glioma susceptibility in a Chinese population. Am J Epidemiol 173:915-922, 2011

12. Claus EB, Black PM: Survival rates and patterns of care for patients diagnosed with supratentorial low grade gliomas: data from the SEER Program, 1973-2001. Cancer 106:13581363, 2006

13. Claus EB, Horlacher A, Hsu L, Schwartz RB, Dello-Iacono $\mathrm{D}$, Talos F, et al: Survival rates in patients with low-grade glioma after intraoperative magnetic resonance image guidance. Cancer 103:1227-1233, 2005

14. Colman H, Zhang L, Sulman EP, McDonald JM, Shooshtari NL, Rivera A, et al: A multigene predictor of outcome in glioblastoma. Neuro Oncol 12:49-57, 2010

15. Cooper LA, Gutman DA, Long Q, Johnson BA, Cholleti SR, Kurc T, et al: The proneural molecular signature is enriched in oligodendrogliomas and predicts improved survival among diffuse gliomas. PLoS ONE 5:e12548, 2010

16. Correa DD, Shi W, Thaler HT, Cheung AM, DeAngelis LM,
Abrey LE: Longitudinal cognitive follow-up in low grade gliomas. J Neurooncol 86:321-327, 2008

17. Costa BM, Ferreira P, Costa S, Canedo P, Oliveira P, Silva A, et al: Association between functional EGF+61 polymorphism and glioma risk. Clin Cancer Res 13:2621-2626, 2007

18. Cox DR: Regression models and life tables. J R Stat Soc B 34:187-202, 1972

19. De Roos AJ, Rothman N, Brown M, Bell DA, Pittman GS, Shapiro WR, et al: Variation in genes relevant to aromatic hydrocarbon metabolism and the risk of adult brain tumors. Neuro Oncol 8: 145-155, 2006

20. De Roos AJ, Rothman N, Inskip PD, Linet MS, Shapiro WR, Selker RG, et al: Genetic polymorphisms in GSTM1, -P1, -T1, and CYP2E1 and the risk of adult brain tumors. Cancer Epidemiol Biomarkers Prev 12:14-22, 2003

21. Egan KM, Nabors LB, Olson JJ, Monteiro AN, Browning JE, Madden MH, et al: Rare TP53 genetic variant associated with glioma risk and outcome. J Med Genet 49:420-421, 2012

22. Egan KM, Thompson RC, Nabors LB, Olson JJ, Brat DJ, Larocca RV, et al: Cancer susceptibility variants and the risk of adult glioma in a US case-control study. J Neurooncol 104:535-542, 2011

23. Everhard S, Kaloshi G, Crinière E, Benouaich-Amiel A, Lejeune J, Marie Y, et al: MGMT methylation: a marker of response to temozolomide in low-grade gliomas. Ann Neurol 60:740-743, 2006

24. Freije WA, Castro-Vargas FE, Fang Z, Horvath S, Cloughesy T, Liau LM, et al: Gene expression profiling of gliomas strongly predicts survival. Cancer Res 64:6503-6510, 2004

25. Guan X, Vengoechea J, Zheng S, Sloan AE, Chen Y, Brat DJ, et al: Molecular subtypes of glioblastoma are relevant to lower grade glioma. PLoS One 9:e91216, 2014

26. Hartmann C, Hentschel B, Tatagiba M, Schramm J, Schnell $\mathrm{O}$, Seidel C, et al: Molecular markers in low-grade gliomas: predictive or prognostic? Clin Cancer Res 17:4588-4599, 2011

27. Hegi ME, Diserens AC, Gorlia T, Hamou MF, de Tribolet N, Weller M, et al: MGMT gene silencing and benefit from temozolomide in glioblastoma. N Engl J Med 352:997-1003, 2005

28. Houillier C, Wang X, Kaloshi G, Mokhtari K, Guillevin R, Laffaire J, et al: IDH1 or IDH2 mutations predict longer survival and response to temozolomide in low-grade gliomas. Neurology 75:1560-1566, 2010

29. Idbaih A, Boisselier B, Marie Y, El Hallani S, Sanson M, Crinière E, et al: TP53 codon 72 polymorphism, p53 expression, and 1p/19q status in oligodendroglial tumors. Cancer Genet Cytogenet 177:103-107, 2007

30. Jakola AS, Myrmel KS, Kloster R, Torp SH, Lindal S, Unsgård G, et al: Comparison of a strategy favoring early surgical resection vs a strategy favoring watchful waiting in lowgrade gliomas. JAMA 308:1881-1888, 2012

31. Jenkins RB, Blair H, Ballman KV, Giannini C, Arusell RM, Law M, et al: A t $(1 ; 19)(\mathrm{q} 10 ; \mathrm{p} 10)$ mediates the combined deletions of $1 p$ and $19 q$ and predicts a better prognosis of patients with oligodendroglioma. Cancer Res 66:9852-9861, 2006

32. Jenkins RB, Wrensch MR, Johnson D, Fridley BL, Decker PA, Xiao Y, et al: Distinct germ line polymorphisms underlie glioma morphologic heterogeneity. Cancer Genet 204:1318,2011

33. Jenkins RB, Xiao Y, Sicotte H, Decker PA, Kollmeyer TM, Hansen HM, et al: A low-frequency variant at 8q24.21 is strongly associated with risk of oligodendroglial tumors and astrocytomas with IDH1 or IDH2 mutation. Nat Genet 44:1122-1125, 2012

34. Jiao Y, Killela PJ, Reitman ZJ, Rasheed AB, Heaphy CM, de Wilde RF, et al: Frequent ATRX, CIC, FUBP1 and IDH1 mutations refine the classification of malignant gliomas. Oncotarget 3:709-722, 2012 
35. Kaloshi G, Benouaich-Amiel A, Diakite F, Taillibert S, Lejeune J, Laigle-Donadey F, et al: Temozolomide for lowgrade gliomas: predictive impact of $1 \mathrm{p} / 19 \mathrm{q}$ loss on response and outcome. Neurology 68:1831-1836, 2007

36. Karim AB, Maat B, Hatlevoll R, Menten J, Rutten EH, Thomas DG, et al: A randomized trial on dose-response in radiation therapy of low-grade cerebral glioma: European Organization for Research and Treatment of Cancer (EORTC) Study 22844. Int J Radiat Oncol Biol Phys 36:549-556, 1996

37. Kesari S, Schiff D, Drappatz J, LaFrankie D, Doherty L, Macklin EA, et al: Phase II study of protracted daily temozolomide for low-grade gliomas in adults. Clin Cancer Res 15:330-337, 2009

38. Kiebert GM, Curran D, Aaronson NK, Bolla M, Menten J, Rutten EH, et al: Quality of life after radiation therapy of cerebral low-grade gliomas of the adult: results of a randomised phase III trial on dose response (EORTC trial 22844). Eur J Cancer 34:1902-1909, 1998

39. Levin N, Lavon I, Zelikovitsh B, Fuchs D, Bokstein F, Fellig Y, et al: Progressive low-grade oligodendrogliomas: response to temozolomide and correlation between genetic profile and O6-methylguanine DNA methyltransferase protein expression. Cancer 106:1759-1765, 2006

40. Lima-Ramos V, Pacheco-Figueiredo L, Costa S, Pardal F, Silva A, Amorim J, et al: TP53 codon 72 polymorphism in susceptibility, overall survival, and adjuvant therapy response of gliomas. Cancer Genet Cytogenet 180:14-19, 2008

41. Liu R, Solheim K, Polley MY, Lamborn KR, Page M, Fedoroff A, et al: Quality of life in low-grade glioma patients receiving temozolomide. Neuro Oncol 11:59-68, 2009

42. Liu Y, Shete S, Etzel CJ, Scheurer M, Alexiou G, Armstrong G, et al: Polymorphisms of LIG4, BTBD2, HMGA2, and RTEL1 genes involved in the double-strand break repair pathway predict glioblastoma survival. J Clin Oncol 28:2467-2474, 2010

43. Louis DN, Ohgaki H, Wiestler OD, Cavenee WK, Burger PC, Jouvet A, et al: The 2007 WHO classification of tumours of the central nervous system. Acta Neuropathol 114:97-109, 2007

44. Lu C, Ward PS, Kapoor GS, Rohle D, Turcan S, Abdel-Wahab O, et al: IDH mutation impairs histone demethylation and results in a block to cell differentiation. Nature 483:474-478, 2012

45. Mainio A, Tuunanen S, Hakko H, Niemelä A, Koivukangas J, Räsänen P: Decreased quality of life and depression as predictors for shorter survival among patients with low-grade gliomas: a follow-up from 1990 to 2003. Eur Arch Psychiatry Clin Neurosci 256:516-521, 2006

46. Malmer B, Adatto P, Armstrong G, Barnholtz-Sloan J, Bernstein J, Claus EB, et al: GLIOGENE: An international effort for delineating the underlying causes of familial glioma. Cancer Epidemiol Biomarkers Prev 16:1730-1734, 2007

47. Malmer B, Feychting M, Lönn S, Ahlbom A, Henriksson R: p53 Genotypes and risk of glioma and meningioma. Cancer Epidemiol Biomarkers Prev 14:2220-2223, 2005

48. Malmer BS, Feychting M, Lönn S, Lindström S, Grönberg $\mathrm{H}$, Ahlbom A, et al: Genetic variation in p53 and ATM haplotypes and risk of glioma and meningioma. J Neurooncol 82:229-237, 2007

49. Nigro JM, Misra A, Zhang L, Smirnov I, Colman H, Griffin $\mathrm{C}$, et al: Integrated array-comparative genomic hybridization and expression array profiles identify clinically relevant molecular subtypes of glioblastoma. Cancer Res 65:1678-1686, 2005

50. Okcu MF, Selvan M, Wang LE, Stout L, Erana R, Airewele $\mathrm{G}$, et al: Glutathione S-transferase polymorphisms and survival in primary malignant glioma. Clin Cancer Res 10:2618-2625, 2004

51. Parsons DW, Jones S, Zhang X, Lin JC, Leary RJ, Angenendt
$\mathrm{P}$, et al: An integrated genomic analysis of human glioblastoma multiforme. Science 321:1807-1812, 2008

52. Phillips HS, Kharbanda S, Chen R, Forrest WF, Soriano RH, Wu TD, et al: Molecular subclasses of high-grade glioma predict prognosis, delineate a pattern of disease progression, and resemble stages in neurogenesis. Cancer Cell 9:157-173, 2006

53. Pignatti F, van den Bent M, Curran D, Debruyne C, Sylvester R, Therasse $\mathrm{P}$, et al: Prognostic factors for survival in adult patients with cerebral low-grade glioma. J Clin Oncol 20:2076-2084, 2002

54. Quinn JA, Reardon DA, Friedman AH, Rich JN, Sampson JH, Provenzale JM, et al: Phase II trial of temozolomide in patients with progressive low-grade glioma. J Clin Oncol 21:646-651, 2003

55. Rajaraman P, Hutchinson A, Wichner S, Black PM, Fine HA, Loeffler JS, et al: DNA repair gene polymorphisms and risk of adult meningioma, glioma, and acoustic neuroma. Neuro Oncol 12:37-48, 2010

56. Rajaraman P, Stewart PA, Samet JM, Schwartz BS, Linet MS, Zahm SH, et al: Lead, genetic susceptibility, and risk of adult brain tumors. Cancer Epidemiol Biomarkers Prev 15:2514-2520, 2006

57. Rajaraman P, Wang SS, Rothman N, Brown MM, Black PM, Fine HA, et al: Polymorphisms in apoptosis and cell cycle control genes and risk of brain tumors in adults. Cancer Epidemiol Biomarkers Prev 16:1655-1661, 2007

58. Rice T, Zheng S, Decker PA, Walsh KM, Bracci P, Xiao Y, et al: Inherited variant on chromosome 11q23 increases susceptibility to IDH-mutated but not IDH-normal gliomas regardless of grade or histology. Neuro Oncol 15:535-541, 2013

59. Sanai N, Berger MS: Glioma extent of resection and its impact on patient outcome. Neurosurgery 62:753-766, 2008

60. Sanson M, Hosking FJ, Shete S, Zelenika D, Dobbins SE, Ma Y, et al: Chromosome 7p11.2 (EGFR) variation influences glioma risk. Hum Mol Genet 20:2897-2904, 2011

61. Schwartzbaum JA, Ahlbom A, Lönn S, Warholm M, Rannug A, Auvinen A, et al: An international case-control study of glutathione transferase and functionally related polymorphisms and risk of primary adult brain tumors. Cancer Epidemiol Biomarkers Prev 16:559-565, 2007

62. Shaw E, Arusell R, Scheithauer B, O'Fallon J, O'Neill B, Dinapoli R, et al: Prospective randomized trial of low- versus high-dose radiation therapy in adults with supratentorial low-grade glioma: initial report of a North Central Cancer Treatment Group/Radiation Therapy Oncology Group/ Eastern Cooperative Oncology Group study. J Clin Oncol 120:2267-2276, 2002

63. Shaw EG, Wang M, Coons SW, Brachman DG, Buckner JC, Stelzer KJ, et al: Randomized trial of radiation therapy plus procarbazine, lomustine, and vincristine chemotherapy for supratentorial adult low-grade glioma: initial results of RTOG 9802. J Clin Oncol 30:3065-3070, 2012

64. Shete S, Hosking FJ, Robertson LB, Dobbins SE, Sanson M, Malmer B, et al: Genome-wide association study identifies five susceptibility loci for glioma. Nat Genet 41:899-904, 2009

65. Shete S, Lau CC, Houlston RS, Claus EB, Barnholtz-Sloan J, Lai R, et al: Genome-wide high-density SNP linkage search for glioma susceptibility loci: results from the Gliogene Consortium. Cancer Res 71:7568-7575, 2011

66. Simon M, Hosking FJ, Marie Y, Gousias K, Boisselier B, Carpentier C, et al: Genetic risk profiles identify different molecular etiologies for glioma. Clin Cancer Res 16:52525259,2010

67. Simon M, Ludwig M, Fimmers R, Mahlberg R, MüllerErkwoh A, Köster G, et al: Variant of the CHEK2 gene as a prognostic marker in glioblastoma multiforme. Neurosurgery 59:1078-1085, 2006 
68. Stege EM, Kros JM, de Bruin HG, Enting RH, van Heuvel I, Looijenga LH, et al: Successful treatment of low-grade oligodendroglial tumors with a chemotherapy regimen of procarbazine, lomustine, and vincristine. Cancer 103:802-809, 2005

69. Tang J, Shao W, Dorak MT, Li Y, Miike R, Lobashevsky E, et al: Positive and negative associations of human leukocyte antigen variants with the onset and prognosis of adult glioblastoma multiforme. Cancer Epidemiol Biomarkers Prev 14:2040-2044, 2005

70. Tosoni A, Franceschi E, Ermani M, Bertorelle R, Bonaldi L, Blatt V, et al: Temozolomide three weeks on and one week off as first line therapy for patients with recurrent or progressive low grade gliomas. J Neurooncol 89:179-185, 2008

71. Turcan S, Rohle D, Goenka A, Walsh LA, Fang F, Yilmaz E, et al: IDH1 mutation is sufficient to establish the glioma hypermethylator phenotype. Nature 483:479-483, 2012

72. van den Bent MJ, Afra D, de Witte O, Ben Hassel M, Schraub S, Hoang-Xuan K, et al: Long-term efficacy of early versus delayed radiotherapy for low-grade astrocytoma and oligodendroglioma in adults: the EORTC 22845 randomised trial. Lancet 366:985-990, 2005

73. Vauleon E, Auger N, Benouaich-Amiel A, Laigle-Donadey F, Kaloshi G, Lejeune J, et al: The 61 A/G EGF polymorphism is functional but is neither a prognostic marker nor a risk factor for glioblastoma. Cancer Genet Cytogenet 172:33-37, 2007

74. Verhaak RG, Hoadley KA, Purdom E, Wang V, Qi Y, Wilkerson MD, et al: Integrated genomic analysis identifies clinically relevant subtypes of glioblastoma characterized by abnormalities in PDGFRA, IDH1, EGFR, and NF1. Cancer Cell 17:98-110, 2010

75. Verhaak RGW, Cooper LAD, Salama SS, Aldape K, Yung WKA, Brat DJ: AACR 2014: presentation abstract: comprehensive and integrative genomic characterization of diffuse lower grade gliomas. April 6, 2014. The Cancer Genome Atlas. (Abstract) (http://cancergenome.nih.gov/newsevents/ events/AACR2014_Abstract_LGGs) [Accessed November $18,2014]$

76. Walsh KM, Anderson E, Hansen HM, Decker PA, Kosel ML, Kollmeyer T, et al: Analysis of 60 reported glioma risk SNPs replicates published GWAS findings but fails to replicate associations from published candidate-gene studies. Genet Epidemiol 37:222-228, 2013

77. Walsh KM, Codd V, Smirnov IV, Rice T, Decker PA, Hansen HM, et al: Variants near TERT and TERC influencing telomere length are associated with high-grade glioma risk. Nat Genet 46:731-735, 2014
78. Wiencke JK, Aldape K, McMillan A, Wiemels J, Moghadassi M, Miike R, et al: Molecular features of adult glioma associated with patient race/ethnicity, age, and a polymorphism in O6-methylguanine-DNA-methyltransferase. Cancer Epidemiol Biomarkers Prev 14:1774-1783, 2005

79. Wrensch M, Jenkins RB, Chang JS, Yeh RF, Xiao Y, Decker PA, et al: Variants in the CDKN2B and RTEL1 regions are associated with high-grade glioma susceptibility. Nat Genet 41:905-908, 2009

80. Wrensch M, McMillan A, Wiencke J, Wiemels J, Kelsey K, Patoka J, et al: Nonsynonymous coding single-nucleotide polymorphisms spanning the genome in relation to glioblastoma survival and age at diagnosis. Clin Cancer Res 13:197-205, 2007

81. Wrensch M, Wiencke JK, Wiemels J, Miike R, Patoka J, Moghadassi M, et al: Serum IgE, tumor epidermal growth factor receptor expression, and inherited polymorphisms associated with glioma survival. Cancer Res 66:4531-4541, 2006

82. Xiao Y, Decker PA, Rice T, McCoy LS, Smirnov I, Patoka JS, et al: SSBP2 variants are associated with survival in glioblastoma patients. Clin Cancer Res 18:3154-3162, 2012

83. Yan H, Parsons DW, Jin G, McLendon R, Rasheed BA, Yuan W, et al: IDH1 and IDH2 mutations in gliomas. N Engl J Med 360:765-773, 2009

84. Yang P, Kollmeyer TM, Buckner K, Bamlet W, Ballman KV, Jenkins RB: Polymorphisms in GLTSCR1 and ERCC2 are associated with the development of oligodendrogliomas. Cancer 103:2363-2372, 2005

\section{Author Contributions}

Conception and design: Claus. Acquisition of data: Claus, Walsh, Bondy, Jenkins. Analysis and interpretation of data: Claus, Walsh, Wrensch. Drafting the article: Claus, Wrensch. Critically revising the article: Claus, Walsh, Molinaro, Wrensch. Reviewed submitted version of manuscript: all authors. Approved the final version of the manuscript on behalf of all authors: Claus. Statistical analysis: Claus. Administrative/technical/material support: Claus, Berger. Study supervision: Claus.

\section{Correspondence}

Elizabeth B. Claus, School of Public Health, Yale University, 60 College St., P.O. Box 208034, New Haven, CT 06520-8034. email: elizabeth.claus@yale.edu. 